\title{
Escola Nova em Montes Claros: apropriações e significados atribuídos à individualização e à socialização (1920-1930)
}

\author{
Geisa Magela Veloso'® \\ Cynthia Greive Veiga"(10 \\ Maria Aparecida Paiva"(D)
}

RESUMO

$\mathrm{O}$ artigo tem por objetivo analisar apropriações dos princípios de socialização e individualização, discutindo incompreensões e temores produzidos no âmbito da Escola Normal Official de Montes Claros e postos em circulação por meio da imprensa local. A discussão situa-se no contexto da Escola Nova, cuja proposta de renovação não aconteceu de forma consensual, mas marcada por embates e conflitos. Constatou-se que os conflitos em torno dos princípios da individualização e da socialização geraram o temor à descristianização da sociedade e a entrada do comunismo pela via da escola.

\section{PALAVRAS-CHAVE}

história cultural; Escola Nova; socialização; individualização. 


\title{
NEW SCHOOL IN MONTES CLAROS: APPROPRIATION AND MEANINGS ATTRIBUTED TO INDIVIDUALIZATION AND SOCIALIZATION (1920-1930)
}

\author{
ABSTRACT \\ via school. \\ KEYWORDS \\ cultural history; New School; socialization; individualization.
}

The article aims to analyze the appropriation of the principles of socialization and individualization, arguing misunderstandings and worries produced under the Escola Normal Official de Montes Claros, and circulated through the local press. The discussion is situated in the context of the New School, whose proposal for renewal did not proceed by consensus, but marked by clashes and conflicts. It was found that the conflicts around the principles of individualization and socialization led to fear of the absence of Christianization in the society and the introduction of communism

NUEVA ESCUELA EN MONTES CLAROS:

APROPIACIONES Y SIGNIFICADOS ASIGNADOS A LA INDIVIDUALIZACIÓN Y SOCIALIZACIÓN (1920-1930)

\section{RESUMEN}

El artículo tiene como objetivo analizar la apropiación de los principios de la socialización e individualización, argumentando malentendidos y temores producidos bajo la Escola Official Normal de Montes Claros y que circulan a través de la prensa local. La discusión se sitúa en el contexto de la Nueva Escuela, cuya propuesta de renovación no procedió por consenso, pero marcado por enfrentamientos y conflictos. Se encontró que los conflictos en torno a los principios de individualización y socialización generan temor de descristianización de la sociedad y la entrada del comunismo a través de la escuela.

PALABRAS CLAVE

historia de la cultura; Nueva Escuela; socialización; individualización. 


\section{INTRODUÇÃO}

O uso das palavras "indivíduo", "individualismo" ou "individualidade" para referir-se às particularidades dos seres humanos é uma ocorrência contemporânea, em que a "individualização" passa a ser compreendida como um traço da "modernidade".

Elias (1994) entende que a modernidade produziu a necessidade de converter o homem em um ser civilizado por meio da transformação que visou formar um novo homem, separando-o de sua "natureza natural", distanciando-o da animalidade e dos comportamentos instintivos, resultando daí a interiorização dos controles sociais. Ao discutir a questão, Varela (2003) afirma que foram produzidas transformações nos códigos de saber, em que a modernidade impulsionou a individualização valendo-se de um processo em que a educação teve papel importante na construção da consciência acerca das particularidades individuais e da percepção de que cada indivíduo é um ser único.

Conforme a autora, para compreensão do processo de individualização, além da interação social que interfere na percepção da individualidade, há que se considerar a questão biológica e psicológica do desenvolvimento humano. Assim, a consolidação do campo da biologia e da psicologia favoreceu a construção da individualização por apontarem as particularidades individuais, que ocorrem não apenas no plano orgânico, mas também na estruturação da personalidade (Varela, 2003).

Para Lourenço Filho (1978), tais discussões situam-se no âmbito da Escola Nova, ${ }^{1}$ que coloca a criança como eixo de sistemas educacionais que deveriam formá-la para viver em sociedade. $\mathrm{O}$ autor entende que é a partir da inserção no mundo e das práticas vivenciadas nas interações com os outros que o indivíduo define sua identidade, percebendo a si mesmo como organismo biológico e ser social, identificando as características que tem em comum com as outras pessoas, mas também se percebendo como ser singular. À medida que os conhecimentos biológicos e psicológicos se aperfeiçoaram, é possível perceber que a formação humana não é independente da organização da vida social e que o desenvolvimento das capacidades individuais encontra-se relacionado às condições sociais e às interações que o indivíduo estabelece com os outros (Lourenço Filho, 1978).

No âmbito da Escola Nova, as práticas de individualização e de socialização se constituíram como eixos da renovação pretendida e não poderiam ser descurados, sob o risco de não se efetivar o desenvolvimento integral do educando. Por isso, a individualização passa a integrar os discursos que visavam à transformação das práticas escolares e à formação do homem moderno - que se percebe singular,

1 Neste artigo, as afirmações acerca dos princípios pedagógicos da Escola Nova se sustentam em Lourenço Filho (1978), pela importância de sua obra Introdução ao estudo da Escola Nova, publicada em 1929 e revista, atualizada e coeditada pelo Ministério da Educação e Cultura (MEC) em 1978. Organizada em três seções e doze capítulos, a obra produziu grande impacto entre os educadores, por permitir elucidar as raízes históricas e as bases técnicas desse movimento de renovação escolar, discutir os sistemas didáticos no entrecruzamento de concepções e modelos práticos e conceituais, além de ainda abordar a problemática educacional situada entre dois polos: dos fins da educação e dos meios empregados para sua operacionalização. 
consciente de suas aptidões e capacidades e, ao mesmo tempo, compreende-se como parte de uma sociedade, desenvolvendo a percepção de si como ser único integrado a um grupo social.

Conforme Lourenço Filho (1978), a individualização e a socialização são princípios centrais para a Escola Nova, por embasarem as práticas de diferenciação individual e de homogeneização social como funções importantes a serem assumidas pelas práticas escolares, porém considerando a necessidade de se respeitar e valorizar as diferenças individuais, o que o autor julga ser um diferencial da Escola Nova em relação à Escola Tradicional. Isso porque, no passado, a educação atuava no intuito de produzir um tipo social uniforme, ou poucos tipos. Já a Educação Nova propõe o respeito aos indivíduos, sem esquecer que a homogeneização é indispensável à coesão para se viver em grupo, pois a assimilação de padrões sociais leva à formação de elementos básicos da personalidade. Contudo, o respeito ao indivíduo gera a necessidade de desenvolver as capacidades individuais, de diferenciá-las e colocá-las a serviço do bem-estar da pessoa e da coletividade (Lourenço Filho, 1978).

Seguindo essa lógica, a escola parte da individualidade, daquilo que cada um é psicológica e biologicamente, e a ela retorna quando houver preparado cada criança para o exercício de suas faculdades (Lopes, s/d.), que se deveria processar pela via de atividades experienciais, como jogos livres, espontâneos e organizados, materiais vivos presentes na natureza, como animais e plantas, além do canto, desenho, música, dança, exploração do meio, reinvenção e interação com a comunidade.

A Escola Nova, conforme Lopes (s/d.), foi concebida como um movimento que se opunha a uma escola intelectualista, convencional e autoritária, posto que a passividade do aluno não condizia com o espírito científico da época. Na proposição dessa nova escola, foi decisiva a contribuição da biologia e da psicologia relativas ao crescimento da criança e seus estágios de maturação, da organização das capacidades de aprender e das diferenças individuais. Nessa nova escola, as ideias de liberdade, individualidade e atividade compõem o tripé sobre o qual se organizam as práticas que irão formar a individualidade humana. "A liberdade se confunde com a democracia: ensinando a liberdade e a convivência democrática acreditava-se preparar a criança para o repúdio a qualquer forma de tirania ou ditadura"(Lopes, s/d., p. 25).

Segundo a autora, no Brasil, a renovação ganha espaço a partir da década de 1920, em um contexto educacional tradicional do ponto de vista dos métodos e conservador, se não reacionário, do ponto de vista político. Para Carvalho (2004b), nesse cenário a escola foi constituída como peça fundamental de um programa de organização nacional por meio da organização da cultura. A autora destaca a grande sedução exercida pela pedagogia moderna, pois seus métodos, centrados na atividade do aluno, eram considerados mais eficientes na consecução desse programa cívico-educacional do que as antigas metodologias. No entanto, a autora considera que foi a proposição de uma educação integral que obteve mais forte apelo, por fazer crítica aos objetivos estritamente instrucionais da escola, pela postulação de uma formação integral, com ênfase moral. E nesse contexto não é possível ignorar a importância da geração de educadores que se notabilizou com o lançamento do Manifesto dos Pioneiros da Educação Nova, que firmou a defesa de um sistema único de ensino e da escola pública, leiga e gratuita. 
Diante do exposto, o presente artigo tem por objetivo analisar as apropriações dos princípios de socialização e individualização, discutindo incompreensões e temores produzidos no âmbito da Escola Normal Official de Montes Claros e postos em circulação por meio da imprensa local. O estudo situa-se no âmbito da história cultural, utilizando como ferramentas para análise da realidade os conceitos de representação, apropriação e prática propostos por Chartier (1990).

Da perspectiva espacial, o estudo tem como referência a cidade Montes Claros, localizada no norte do estado de Minas Gerais, considerada polo econômico e cultural regional. O recorte temporal, que incluiu os últimos anos da década de 1920 e primeiros da década subsequente, deveu-se a questões locais, apesar de não desconsiderar o contexto mais amplo, com o qual dialoga e do qual recebe influências. No referido período, Montes Claros vivia um momento de grande efervescência cultural, em que sua intelectualidade, sobretudo a ligada à Escola Normal Official e ao jornal Gazeta do Norte, produzia e fazia circular ideias relativas à Escola Nova em seus propósitos de renovação e mudança.

Para exemplificar algumas das ideias veiculadas, é importante lembrar que na década de 1920 o jornal Gazeta do Norte se orientou pela denúncia de problemas de diferentes ordens e pela propaganda dos benefícios advindos da alfabetização, da instrução e da educação. Visando ao progresso, o jornal engendrou o ler e escrever como condição para o desenvolvimento individual, para a saída das trevas da ignorância e adoção de um padrão de comportamento educado, típico de uma cidade moderna e civilizada. Na década de 1930, por influência da Escola Nova, o jornal adensou a discussão e redimensionou sua missão educativa. Além de defender a necessidade de ensinar a ler e escrever, o jornal desenvolveu ações com o intuito de interferir na sala de aula e modificar as práticas alfabetizadoras. Pela negação de sistemas sintéticos, o jornal defendia métodos analíticos de alfabetização, bem como a adoção de novos recursos e materiais didáticos, por considerar que a leitura deveria priorizar a compreensão dos textos lidos e ser utilizada para aquisição de conhecimentos.

Outra faceta da missão educativa da Gazeta do Norte foi a educação da família, em que a mulher era compreendida como peça-chave da modernidade, sendo então necessário educá-la para que pudesse educar as novas gerações. A mulher moderna deveria educar-se, apropriar-se de conhecimentos científicos e tornar-se capaz de utilizar métodos menos coercitivos e mais operativos para a obtenção da obediência, do respeito e da disciplina das crianças. Liberdade e autodisciplina passaram a ser vistas como traços característicos de uma educação moderna, não punitiva e não coercitiva, em que a aplicação de castigos era condenada como prática educativa por constituir-se como desrespeito à criança e a sua individualidade. O jornal ainda defendia a necessidade de que cidadãos montes-clarenses fossem educados de forma integral, para perceberem sua singularidade como pessoas, desenvolvendo aptidões individuais e adaptação ao meio social.

Por sua atuação em Montes Claros, o jornal Gazeta do Norte foi tomado como fonte documental para a reconstituição da memória coletiva. No período estudado, o jornal conferiu visibilidade para discussões em curso na Escola Normal Official de Montes Claros e permitiu a análise de sentidos díspares em torno dos princípios de 
socialização e individualização, revelando apropriações diferenciadas de conteúdos culturais. Ao discutir tais significações, o fazemos com base em publicações de alunas e professores da referida escola normal. No entanto, para analisar apropriações não autorizadas dos conceitos de individualização e socialização, foi considerado um único sujeito, Francisco Floriano de Paula, e um único texto, o discurso por ele proferido para as normalistas montes-clarenses em janeiro de 1935.

A importância operatória dessa discussão, para a compreensão das práticas culturais, associa-se ao fato de que as ideias de Francisco Floriano de Paula, ao serem publicadas pelo jornal Gazeta do Norte, tiveram ampliada a sua circulação no tempo e no espaço, não se circunscrevendo aos limites de uma festa de formatura. Conforme Chartier (2001), o conceito de apropriação pode ser inscrito no centro da história cultural por indicar o que os sujeitos sociais fazem com o que recebem. Apropriação é, para o autor, um uso criador, uma forma de invenção e produção dos leitores ao se apoderarem de um texto. Uma apropriação indica, portanto, processos pelos quais os sujeitos produzem sentidos diferentes para os textos lidos, demarcando pluralidade de usos e multiplicidade de interpretações (Chartier, 2001).

Para Chartier (1990, p. 123), é tarefa do historiador identificar a diversidade das "leituras antigas", buscando reconhecer as estratégias pelas quais autores e editores tentaram impor uma ortodoxia do texto, uma leitura forçada. "Orientado ou colocado numa armadilha, o leitor encontra-se, sempre, inscrito no texto, mas, por seu turno, este inscreve-se diversamente nos seus leitores". Abordar as leituras que fazem os sujeitos é considerar, ao mesmo tempo, a irredutível liberdade dos leitores e os condicionamentos que pretendem refrear sua compreensão (Chartier, 1990).

Neste artigo, tomar o conceito de apropriação para analisar as representações de Francisco Floriano de Paula acerca dos princípios de socialização e individualização implicou considerar que os sentidos não estavam inscritos nos textos sobre a Escola Nova e que estes não foram compreendidos de uma única maneira por todos. Afinal, os sujeitos que deles se apropriam são distintos, portadores de experiências e conhecimentos diversos construídos a partir de trajetórias múltiplas.

Para melhor apresentação das ideias, o artigo foi organizado em quatro movimentos. Na primeira seção situamos a socialização e a individualização no contexto da Escola Normal Official de Montes Claros, explicitando as apropriações produzidas por seus professores e alunas, para em seguida, na segunda seção, discutirmos as apropriações de Francisco Floriano de Paula, as quais revelam seu temor em relação à descristianização da sociedade e a entrada do comunismo pela via da escola. Já na terceira seção do artigo produzimos uma análise do contexto em que essas ideias circularam, buscando compreender os receios de Francisco Floriano de Paula a partir da relação entre Igreja e Estado, no âmbito da renovação educacional proposta por Minas Gerais. Na quarta e última seção, apresentamos reflexões mais amplas, em que o contexto político e social brasileiro se apresenta como possível chave explicativa para os receios em relação à socialização e individualização como princípios defendidos pela Escola Nova. 


\section{INDIVIDUALIZAÇÃO E SOCIALIZAÇÃO NA ESCOLA NORMAL DE MONTES CLAROS}

Discutir princípios e proposições da Escola Nova implica pensar, como afirma Lourenço Filho (1978), que esse é um movimento não homogêneo, uma proposta entrecortada por elementos consensuais, mas também por ideias concorrentes e contraditórias.

Em Montes Claros, norte de Minas Gerais, o jornal Gazeta do Norte fez circular ideias e princípios educativos visando modificar as práticas de pais e professores, sendo, a partir dos últimos anos da década de 1920, tais ideias guiadas pelos princípios da Escola Nova. Em 1927 o jornal publicou o discurso de formatura de Geraldina Alves, aluna da Escola Normal de Montes Claros, que enfatizava a necessidade de respeito às diferenças individuais da criança. Orientada por conhecimentos da biologia e da psicologia, a normalista considerava que, a partir da Escola Nova, a responsabilidade das escolas havia se ampliado - às professoras estava reservado um "cargo altruísta de finalidades vastas", que lhes exigia "amar a creança, estudal-a, entender-lhe a psycologia, orientar-lhe de forma carinhosa e clarividente a forma da personalidade" (Alves, 1927, p. 4).

Nas representações da normalista havia uma preocupação com as finalidades sociais da educação, por ela consideradas instrumento para o desenvolvimento das aptidões individuais e adaptação dos indivíduos aos papéis sociais. A aluna destacou que, ao direcionar a atenção para o indivíduo, a educação não visava a interesses particulares - o respeito à individualidade significava favorecer a diferenciação e o desenvolvimento de aptidões individuais, uma preocupação com finalidades socialmente definidas e inseridas no processo de civilização e progresso social.

Para a normalista, a sua alegria e também a de todas as outras professoras somente se tornariam concretas quando pudessem ver o espírito juvenil se aperfeiçoar pela "cultura sadia e indispensável" e "da creança illetrada surgir o indivíduo culto, útil, emancipado, forte" (Alves, 1927, p. 4). Ou seja, a escola era a instituição capaz de promover a instrução e efetivar as transformações individuais e sociais que produziriam a cidade civilizada. E o professor era o agente dessa transformação, pois da instrução "depende o futuro da raça e o logar de destaque que devemos occupar no conceito das nações e dos povos civilisados" (Alves, 1927, p. 4).

Essas representações da normalista revelam uma apropriação de princípios da Escola Nova em circulação naquele momento histórico, em que a educação deveria favorecer o desenvolvimento de aptidões individuais. No ano de 1934, o jornal $G a-$ zeta do Norte retomou a discussão, sendo possível perceber uma maior explicitação dos princípios escolanovistas. Ao proferir conferências destinadas à educação das famílias montes-clarenses, o professor José Raymundo Netto, diretor da Escola Normal Official de Montes Claros, afirmou ser necessário que todos os educadores compreendessem bem o ideário da Escola Nova e "o princípio cardeal que a orienta: - Liberdade e respeito à individualidade da criança!” (Netto, 1934, p. 2).

Visando produzir um novo olhar sobre a educação da infância, o professor José Raymundo Netto construiu argumentos valendo-se de conhecimentos da biologia e da psicologia para assim discutir temas diversos, como hereditariedade, iniciativa e interesses infantis, aplicação de castigos, recalcamento e sublimação 
dos instintos. Para o professor, era necessário organizar práticas educativas menos rígidas, pela não aplicação de castigos, com base na atividade infantil interessada, que produziria a autodisciplina e o controle dos instintos e desejos. Era necessário que o ambiente em torno da criança fosse rico em estímulos capazes de atender a seus interesses e favorecer o desenvolvimento pleno. A criança precisava viver intensamente sua infância para tornar-se um adulto saudável, de corpo e de espírito (Netto, 1934).

Em defesa da liberdade da criança e do respeito à sua individualidade, os argumentos de José Raymundo Netto eram coerentes com as ideias escolanovistas em curso naquela época, que pretendiam produzir o homem civilizado, consciente de suas particularidades como pessoa, que exercia uma liberdade alicerçada na autodisciplina e na separação da sua "natureza natural" pelo controle dos comportamentos instintivos.

Conforme Lourenço Filho (1978), em busca de uma compreensão global e unitária da criança, o conhecimento objetivo favorecido pela biologia estabeleceu noções importantes acerca do crescimento, da maturação, do condicionamento endócrino e do condicionamento nervoso. Mas a adaptação da criança não se limitava a esses aspectos, cuja compreensão dependia das relevantes contribuições da psicologia, que se desenvolveu a partir da própria biologia. Conforme o autor, a individualização inicia-se desde cedo, por um processo em que a criança representa uma pessoa entre as demais, com elas estabelecendo formas de comunicação, ação e reação. Pela lógica da individualização, a criança é compreendida como ser singular, no entanto a estruturação de sua personalidade não se processa no isolamento, mas na interação com as pessoas.

Por essa necessária relação do individual com o coletivo, a socialização apresentava-se como outro princípio orientador das práticas educativas renovadas. Lourenço Filho (1978) considera que uma situação de ensino deveria ser sempre uma atividade de cooperação social, pois a existência mental depende da interação do organismo com o meio físico e da pessoa com o seu grupo. Assim, a escola deveria organizar-se na forma de comunidade, tendo em vista as necessidades da vida em comum, por um sistema em que liberdade, atividade e responsabilidade fossem exercidas na vida social - de onde se conclui que a atividade cooperativa era importante na escola porque o era na vida social.

Ainda conforme o autor, inicialmente a renovação das práticas educativas colocou ênfase nos recursos didáticos e métodos de ensino, somente se preocupando com as finalidades sociais da educação a partir da Primeira Guerra Mundial. Como efeito da guerra, produziu-se a consciência de uma dependência entre povos e nações, apontando, sobretudo, para a necessidade de se reverem princípios de educação e suas instituições, visando à preservação da paz (Lourenço Filho, 1978).

Em Montes Claros, por essa compreensão das finalidades sociais da educação, em 1927, ao proferir discurso de formatura, Geraldina Alves revelou estar consciente do alerta deixado pela guerra: o conflito indicou para a humanidade que os homens ainda não haviam atingido um elevado grau de civilização. A normalista conclamava suas colegas para o cumprimento do "sagrado dever de instruir a população", mas considerou que não bastava alfabetizar e instruir para se chegar ao estado de civi- 
lização desejado, era necessário que o homem se apropriasse de princípios éticos, morais e religiosos, para aprender a viver em grupo (Alves, 1927, p. 4).

A grande guerra foi uma tremenda lição porque provou a Humanidade, entre outras verdades que o homem não attingiu o supremo grau de civilisação, fugindo-lhe assim a conquista da felicidade, dentro da justiça e da fraternidade humana! E que sêde de saber apodera-se do mundo, parallelamente aos grandes princípios ethicos e religiosos, sem os quaes todas as conquistas humanas estão condenadas ao descalabro e dissolvimento! (Alves, 1927, p. 4)

Por essa lógica, a escola não se poderia ocupar apenas de instruir as novas gerações. Era necessário rever finalidades educativas favorecendo a interação humana e a construção de valores sociais, como justiça e fraternidade, sem as quais as conquistas da ciência não fariam sentido. Como resultado da guerra, houve a necessidade de integração entre os povos, de favorecer o sentimento de cooperação e solidariedade, tornando a escola um espaço de socialização, de interação e trabalho coletivo.

Na década de 1930, no jornal Gazeta do Norte, as discussões em torno das finalidades sociais da educação encontraram maior espaço nas publicações. Em 1933, em sua "Collumna Pedagógica", o jornal publicou um artigo de Idoleta Maciel, aluna do curso de aplicação da Escola Normal Official de Montes Claros, que declara: "o objectivo das nossas escolas é socializar a criança, isto é, dar-lhe um comportamento condiccionado ao seu meio social, tornando-a apta para reagir a todos os estímulos e reações que este lhe offerece" (Maciel, 1933, p. 2).

Em artigo de Augusta Guimarães, também aluna do curso de aplicação, é abordada a necessidade de favorecer condições para a socialização, por meio de atividades escolares que imitassem situações concretas da vida cotidiana. Isso porque:

Socializar é fazer viver a própria vida do meio escolar, nas aulas, nas excursões, nos auditoriuns, dando oportunidade ao desenvolvimento da personalidade dos alumnos e criando para todos, ricos e pobres, occasiões de sentirem que são filhos de uma terra onde não há castas sociais. Esta deve ser a socialização da escola brasileira. (Guimarães, 1933, p. 1)

No ano de 1934, em conferência destinada às famílias e publicada no jornal Gazeta do Norte, José Raymundo Netto enalteceu a educação social, que se deveria basear na "humanidade, auxílio-mútuo, confraternização, espírito de cooperação e livre expansão da personalidade; únicos factores capazes de preparar o mundo para advertir da Paz entre os homens" (Netto, 1934, p. 2).

No ano seguinte, ao proferir discurso de formatura em homenagem às normalistas, o professor José Raymundo Netto retomou a questão e esclareceu que a socialização representava uma abordagem pedagógica, pela qual a escola se organizaria pelo trabalho em comunidade, de forma que pudesse "ensinar praticamente aos homens do futuro que a união faz a força, que o espírito de solidariedade e de 
cooperação é a condição básica para o soerguimento de um povo e para a grandeza de uma raça!" (Netto, 1935, p. 2).

Pelos sentidos atribuídos à socialização, as situações didáticas deveriam familiarizar as crianças com os desenvolvimentos reais que ocorriam na sociedade em mudança, dos quais não poderiam vivenciar de forma direta. Nas representações de Jenny Canella, aluna do curso de aplicação:

As nossas sociedades de hoje ganharam uma tal complexidade que a participação directa da criança na vida adulta se torna absolutamente impossível. Nasce daí a necessidade da escola para fornecer aquillo que a vida, directamente, não pode ministrar. E é assim que a vida social se perpetua através da escola. Cumpre, por conseguinte, que a escola se transforme n'um ambiente simplificado, purificado e favorável à confraternização, onde a criança, paulatinamente, vá fazendo a synthese das complexas experiências humanas. (Canella, 1933, p. 1)

Essas foram elaborações produzidas à luz da Escola Nova. Com as atividades coletivas, o objetivo da escola era socializar a criança e o jovem, condicionar-lhe novos hábitos, inculcar-lhes valores e atitudes adequadas ao seu meio, produzir a disciplina e a adaptação de seus comportamentos, favorecendo a estruturação de sua personalidade. Conforme a normalista Augusta Guimarães, eram dois os processos pelos quais se poderia socializar a criança: de um lado, a imitação das atividades do meio, que poderia ser facilitada pela organização de instituições escolares; de outro, a realização de excursões e de projetos (Guimarães, 1933).

A organização das atividades deveria ter como referência os princípios do método ativo que, para a normalista, era "o único socializador". Era necessário considerar as exigências do meio e adaptar os programas; observar o critério de autonomia da criança e respeitar-lhe a personalidade, favorecendo o trabalho solidário, o espírito de cooperação, o respeito aos direitos individuais e a alegria coletiva (Guimarães, 1933, p. 1).

Augusta Guimarães também discutiu os equívocos relacionados à utilização pedagógica de auditórios. O primeiro era pensar que somente por meio de auditórios seria possível a socialização. O segundo associava-se ao seu modo de organização, pois não se explorava o potencial socializador dessa atividade: em vez de contar com a colaboração dos alunos, a professora apenas determinava a execução de tarefas - mandando decorar certos números, distribuindo papéis, determinando horário e local de realização. Mas, agindo dessa forma, "é nesta instituição escolar que a professora vem mostrar que sua escola não socializa” (Guimarães, 1933, p. 1).

Essas preocupações com a realização de auditórios também foram identificadas na Revista do Ensino. Em 1933, J. Madureira orientava as professoras acerca da realização de atividades socializadoras, destacando determinações do Regulamento do Ensino, que: 
[...] sabiamente instituiu: auditórios, clubs de leitura, socialização, dramatização, hora de historia, correio infantil, jornais escolares, cozinha e merenda escolares, excursões, teatros, festas, liga de bondade, escoteirismo, ensino por meio de jogos, trabalhos manuaes, etc. (Madureira, 1933, p. 8)

A Revista do Ensino considera que todas essas atividades somente produziriam efeitos educativos se fosse considerada a iniciativa das crianças, cabendo ao educador auxiliar, orientar e dirigir. Quando as crianças apenas executassem as ordens do professor, os resultados do trabalho poderiam até ser brilhantes, mas sem nenhum "resultado compensador". Isso porque, na realização de uma atividade, mais importava o processo de desenvolvimento que o resultado em si (Madureira,1933).

Em síntese, para os defensores da Escola Nova, a individualização significava respeito às diferenças individuais, liberdade da criança e iniciativa individual, enquanto a socialização assumia o sentido de interação e adaptação social, pela imitação de práticas ou pela inserção do educando em situações sociais reais.

\section{TEMORES E CONFLITOS ACERCA DA SOCIALIZAÇÃO E DA INDIVIDUALIZAÇÃO}

A socialização como abordagem pedagógica esteve presente nas preocupações do jornal Gazeta do Norte, que procurou interferir nas práticas pedagógicas das escolas. As publicações do jornal revelam uma apropriação referenciada pelos princípios escolanovistas, que atribuem à socialização o sentido de trabalho cooperativo e em comunidade, visando à adaptação social.

Contudo, em Montes Claros, identificamos apropriações diferenciadas, que indicam incompreensões acerca dos significados atribuídos à socialização, em que disputas por representações produziram tensões e temores. Ao discursar para as formandas da Escola Normal Official de Montes Claros, em 1935, o assistente técnico do ensino em Minas Gerais, Francisco Floriano de Paula, apresentou uma leitura distinta dos princípios de individualização e socialização, por ele denominados de "individualismo" e "socialismo", associados ao egoísmo individualista e às práticas políticas comunistas ou socialistas.

Em seu discurso, Francisco Floriano de Paula revelou preocupações com a implantação de ideias socialistas e comunistas na escola. Na condição de paraninfo, que havia exercido as funções de professor e diretor da Escola Normal Official de Montes Claros até o mês de junho de 1933, Francisco Floriano de Paula admitiu erros que havia cometido, revisou ideias que ele próprio havia defendido, teceu críticas ao modo confuso e aligeirado como alguns conteúdos foram ensinados e, por fim, defendeu a orientação pedagógica cristã, para ele a única capaz de promover a educação integral dos indivíduos (Paula, 1935, p. 2).

Francisco Floriano de Paula entendia que levar em conta interesses e necessidades individuais e omitir-se acerca de questões espirituais, a individualização, por centralizar-se na pessoa, era uma "funesta" orientação para a ação educativa. 
Pelo individualismo, que faz do indivíduo o centro de toda a vida e de que se acha pejada a literatura pedagógica de Locke, Rousseau, Kant e outros, vemos que o homem só é considerado na vertical, desenvolvendo-se biologicamente e modificando-se psicologicamente na lucta pela vida. $\mathrm{O}$ indivíduo é considerado o creador da própria sociedade. Razão, consciência, liberdade, evolução, individualidade, autonomia e independência do indivíduo são suas palavras mágicas na ordem espiritual e na ordem econômica. E o "homo omini lupus" marcou a característica de tão funesta orientação philosophica para os destinos da educação. (Paula, 1935, p. 2)

No discurso do professor é evidenciada a necessidade de reorientação filosófica da educação. Em suas palavras, a centralidade no indivíduo produziria uma prática educativa voltada apenas para o desenvolvimento da natureza biológica e psicológica, que desconsiderava a dimensão espiritual do ser humano e sua natureza transcendente. Segundo ele, o "individualismo" era uma ideia conflitante no interior do próprio movimento de renovação educacional.

Como reação ao individualismo surgiu a corrente sociológica, considerando a sociedade como um organismo vivo, do qual o homem era ínfima parcela. Ahi o indivíduo desenvolve-se biologicamente e modifica-se psicologicamente para a vida em sociedade, isto é, cresce no sentido horizontal para o nivelamento total com os demaes indivíduos. (Paula, 1935, p. 2)

Contudo, na concepção de Francisco Floriano de Paula, o socialismo também não era alternativa teórica adequada para orientar a ação educativa. A sua defesa encaminhou-se para a preservação dos valores cristãos na educação da infância; sua preocupação era com um tipo de educação que poderia corromper a formação e produzir a descrença nos valores espirituais.

Colhido de surpresa, sem preparo algum de phylosophia educacional, o nosso professorado passou a sofrer um processo de lenta formação mental, em que o individualismo e o socialismo pedagógicos, antagônicos nos princípios fundamentaes, mas unissomos na faina de nos corromperem a intelligencia e o coração, exerceram tenaz e silenciosa collaboração atravez dos livros comprados a esmo e atirados nas nossas bibliothecas e das divulgações pedagógicas falhas de systematização phisolophica accorde com a nossa concepção de vida. Foi assim que vimos de um momento para outro Rousseau e de Dewey, de Spencer e Natorp casados em nossas aulas de pedagogia, onde o professor, embevecido pelos encantos dos methodos activos, transformou-se em dócil vehiculo de idéas abaladoras de nossa estructura social. (Paula, 1935, p. 2)

Ainda, para o assistente técnico do ensino, o professorado tornara-se alvo fácil de "enganadoras teorias" em virtude de suas "leituras apressadas" e desprovidas de reflexão. Tais teorias acenavam novidades, mas pretendiam corromper as tradições, abolir o princípio da autoridade e usar a escola como instrumento da descristianização da infância e da juventude. 
Despercebidas a principio, pelos effeitos anesthesicos da novidade, as conseqüências apresentaram-se depois em cores nítidas, na abolição do principio da autoridade e no despreso dos critérios de valor estabelecidos pela moral e pela razão. À escola tradicional, que com seus maus methodos e processos de ensino visava precipuamente a formação do caráter, ou seja, o fortalecimento da vontade do homem e do cidadão para a realização de seus fins natural e sobrenatural, substituiu-se a escola socializadora, que os manuaes de pedagogia socialista destinam à simples preparação da creança para a vida em sociedade, considerada fim único do homem esquecidos seus auctores que a socialização completa só é possível em situação total.

A tendência disciplinadora da educação, observada pela Igreja com o enrijecimento da vontade para o serviço de Deus, opuzeram outras de caracter naturalista, psichologico, scientifico ou sociológico visando sobretudo a derrogação do principio de auctoridade. E o commodismo na esphera das responsabilidades moraes do professor, pela incomprehensão de leituras apressadas e sem cuidadosa meditação; foi solapando as nossas mais bellas tradicções, inclusive a fé que enrijara a alma dos nossos avós para os mais rudes embates da vida. (Paula, 1935, p. 2)

O paraninfo afirmou a importância da formação obtida na Escola Normal, no entanto a utilização dos conhecimentos teóricos implicava bom senso e discernimento. Pela compreensão de Francisco Floriano de Paula, duas possibilidades se apresentariam às futuras professoras. A primeira seria o "aniquilamento das mais justas aspirações e dos mais nobres ideais", ao se depararem com a agitação do meio social e das "forças díspares" que iriam interferir em sua capacidade para agir. A segunda alternativa seria o robustecimento, na consciência, da certeza de possuírem uma capacidade de ação e de se constituírem em força intencionalmente preparada para realizar as modificações reclamadas pela virtude e pelo progresso (Paula, 1935, p. 2).

Para o professor, as escolas normais estavam passando por um momento de indefinição e confusão. $\mathrm{Na}$ ansiedade de se mostrarem em sintonia com as modernas teorias e métodos pedagógicos da Escola Nova, os professores se esqueciam de levar em conta o quadro natural e social do Brasil, um país católico e não comunista. Francisco Floriano de Paula deixou evidente sua preocupação com a futura atuação das formandas, fazendo ressalvas no que julgava equivocado no interior "do confuso campo de nossos trabalhos educacionais”. Para ele, orientado por concepções oriundas da "extrema esquerda da Escola Nova", o quadro era de um "verdadeiro desnorteamento", que exigiria das professoras discernir, entre as abordagens renovadoras, aquelas que fossem capazes de orientar as mudanças necessárias à educação, sem a perda dos princípios e dos valores morais, que fundavam as crenças religiosas e as concepções de vida da família mineira (Paula, 1935, p. 2). 
É fora de qualquer dúvida que reina nos meios do ensino, o mais constristador desnorteamento. As profundas modificações trazidas pela escola activa aos nossos archaicos methodos e processos de instrucção, vieram acompanhadas de postulados philosophicos dictados pela extrema esquerda da Escola Nova, onde as mais acentuadas tendências socialistas fixaram os seus arraiaes, na esperança de fazer da escola o seguro instrumento de sua infernal política de descristianização do mundo. (Paula, 1935, p. 2)

Francisco Floriano de Paula era favorável à renovação dos métodos de ensino, que facilitaria a aprendizagem, mas a mudança deveria ser guiada pela filosofia cristã - que visava educar e fortalecer a fé e a vontade para servir a Deus.

Dentro das diretrizes da escola e dos methodos activos, deveis enquadrar os vossos conhecimentos de ordem technica, pois inegável tem sido o progresso da sciencia pedagógica deante das pesquisas de caracter biológico, psicológico e sociológico. A pedagogia experimental, a que a psichologia e a sociologia educacionaes têm prestado os mais relevantes serviços, offerece-nos uma contribuição inestimável de methodos e processos que facilitam extraordinariamente o aprendizado. $\mathrm{O}$ emprego consciencioso destes meios é dever imposto a todo professor que se honra da cathedra que occupa. Mas apoderar-se de tão úteis instrumentos para realizar a obra impatriótica de crear no Brasil uma mentalidade avessa às nossas tradições de ordem e cultura, oriundas de postulados que a civilização latina nos legou, é falsear a função da escola em nosso meio e transformal-a em fonte de idéas comprometedoras da unidade nacional e da grandeza da Pátria, pela derrocada das grandes forças moraes da nacionalidade. (Paula, 1935, p. 2)

O professor Floriano de Paula defendia a efetivação de reformas no campo educacional compreendendo ser necessário implantar um projeto que representasse tradição e mudança. Contudo, a renovação nos métodos de ensino não poderia perder de vista o conjunto de valores e concepções de vida cristã. Uma vez que a formação das professoras estava "eivada de princípios destoantes", nas representações de Francisco Floriano de Paula, a solução era distinção entre os meios técnicos e os fins da educação. Dessa forma, as professoras seriam capazes de promover mudanças no modo de ensinar, colocando a atividade da criança como base de sua aprendizagem, sem perder de vista a necessária formação moral e espiritual. $\mathrm{O}$ acesso à cultura e à aprendizagem dos conhecimentos escolares se daria pela utilização dos métodos ativos - os meios -, em consonância com os princípios católicos de espiritualidade, de ordem moral, de disciplina e respeito - os fins da educação (Paula, 1935).

Por essa diferenciada apropriação dos princípios escolanovistas, Francisco Floriano de Paula identificou finalidades socialistas e comunistas inscritas na Escola Nova, mas não desqualificou os conhecimentos de ordem técnica que a embasavam. Em suas representações, a psicologia, a biologia e a sociologia prestavam inestimáveis serviços ao campo educacional, possibilitando a renovação de métodos de ensino. 
Porém era perigosa a apropriação "não conscienciosa" desses conhecimentos pelas professoras que no exercício de sua profissão poderiam comprometer a formação das novas gerações, desestruturar a unidade nacional e a grandeza da Nação, utilizando o saber técnico como instrumento na derrocada dos valores morais, religiosos e espirituais (Paula, 1935).

Daí ser necessário o discernimento das professoras, para poderem lançar um olhar perscrutador sobre as finalidades educativas, inovar os métodos, mas desenvolver uma ação pedagógica comprometida com os valores e princípios postulados pela tradição nacional católica. Nesse sentido, o paraninfo deixa seu conselho para as formandas:

"Examinae tudo; conservae o que é bom”. Mas em questões de fins da educação procurae traçar as diretrizes de vosso exercício magisterial pelos marcos indeléveis da philosophia pedagógica christã, cujas normas se acham consubstanciadas na notável encíclica de S. S. o Papa Pio XI, "Acerca da educação christã da juventude". (Paula, 1935, p. 2)

Pela visão católica de Francisco Floriano de Paula, os pressupostos filosóficos e as finalidades educativas da Escola Nova estavam equivocados e não eram capazes de promover a educação integral, que somente se daria quando o indivíduo, dentro do corpo social, pudesse crescer verticalmente pela igualdade de oportunidades e, no sentido horizontal, desenvolver-se para servir a Deus.

Vêde agora o quadro magistral da orientação pedagógica fixada pela "philosophia perenis" em que o respeito à personalidade humana, pela constante exigência de sua affirmação no seio da sociedade, se alia à idéa da Comunidade Christã, onde o indivíduo cresce verticalmente pela igualdade de opportunidade para todos e horizontalmente serve numa constante prova do "ama a teu próximo como a ti mesmo". Nesta perfeita concepção de vida resulta o verdadeiro conceito de educação integral, o indivíduo, dentro do corpo social, desenvolve-se biologicamente e modifica-se phisichologicamente para Deus. Por Christo chega-se a Deus, e a Christo atravez dos sábios ensinamentos da Igreja, diz Hovre. (Paula, 1935, p. 2)

A educação integral defendida pelo professor Francisco Floriano de Paula era orientada por um "escolanovismo católico", com exigências de ordem física, moral e espiritual. Em sua visão, "individualismo" " "socialismo" eram considerados perniciosos à formação das crianças e, consequentemente, para a construção da unidade nacional e grandeza da nação brasileira.

Lançae os vossos olhos perscrutadores para o campo de finalidades educativas que vos têm sido apresentado e vereis invariavelmente, ora em antagônicas posições, ora de mãos dadas em comprometedora symbiose, o individualismo e o socialismo pedagógicos oppondo-se por todos os meios à verdadeira compreensão dos objectos da educação. Analisae, porem, as características de cada um e observareis que a educação integral tão propalada por seus adeptos, não se comporta nos âmbitos estreitos de suas concepções. (Paula, 1935, p. 2) 
Ao falar para suas ex-alunas, o professor pretendia preveni-las contra as finalidades socialistas e comunistas, que considerava presentes na ideia de socialização. No entanto, as alunas da Escola Normal já conheciam essas preocupações. Em artigo intitulado "Socializar a creança", publicado pelo jornal Gazeta do Norte, em abril de 1933, época em que o professor Floriano era diretor da Escola Normal e professor de metodologia e prática de ensino, a aluna Augusta Guimarães esclareceu a origem do princípio da socialização apontando as más interpretações em torno de seu significado pedagógico. Em suas palavras:

A idéia de socialização partiu de um grupo de homens de grande experiência educativa. Mas infelizmente tem sido combatida por maus interpretadores e pelos defensores da escola tradicional. Acham uns que preparar a creança para a vida actual é restringir-lhe o campo de acção, diminuir-lhe o crescimento das experiências. Outros entendem que a idéa pretende atingir o comunismo pela escola. Nenhuma das afirmações tem valor. Pela socialização há uma adaptação progressiva da creança ao seu meio; se este evolue, a creança o acompanha. (Guimarães, 1933, p. 1)

Por essas ideias fica evidente que a aluna havia se apropriado do conceito de socialização pela visão pretendida pelos propugnadores da Escola Nova - como processo de adaptação da criança ao seu meio social. Também fica evidente que a normalista conhecia os temores de utilização da escola como instrumento para a implantação do comunismo. Em suas representações, a missão da escola era socializar a criança, "educando-a nos critérios de realidade e valor do seu meio", pela aquisição de um "comportamento condicionado ao meio", pela transformação da escola em uma miniatura da sociedade, "[...] mas a miniatura de experiências simplificadas, sem vícios e competições mesquinhas” (Guimarães, 1933, p. 1).

A aluna destacou que os métodos da Escola Ativa eram os únicos capazes de favorecer a socialização, não concordando com a utilização política da escola como instrumento para implantação do comunismo e não comungando dessa inquietação.

A socialização deseja crear na escola o trabalho solidário, o trabalho em comunidade, fixando nas creanças a idéa de que não podemos prescindir hoje do trabalho dos nossos semelhantes, mas isto não é comunismo, é a vida de todas as sociedades. Naturalmente, se a sociedade é comunista, como a Rússia, a escola o será, pois tem que se amoldar ao meio, mas entre nós isso seria desvirtuar a idéa de socialização, isto é comportamento condicionado ao meio. (Guimarães, 1933, p. 1)

A normalista revelou conhecer as apropriações diversas em torno da socialização, mas não acreditava na implantação do comunismo pela via das atividades socializadoras. A preocupação estava diretamente voltada para o aspecto pedagógico e, por isto, destacava elementos fundamentais para a introdução das mudanças socializadoras, quais sejam: a necessidade de reformulação dos programas de ensino, a adoção dos métodos ativos para o ensino, a vivência de experiências reais de aprendi- 
zagem, o conhecimento do meio social pelo professor, a realização de atividades em colaboração, a observação da disciplina e autonomia da criança (Guimarães, 1933).

Em nosso estudo, por entendermos, com Chartier (1990), que a história cultural é a história das representações e das práticas, tornou-se central analisar as apropriações que os sujeitos sociais fizeram dos conteúdos postos em circulação, que alimentaram a produção dessas representações e práticas. Ou seja, entender a problemática do "mundo como representação" exigiu certa reflexão sobre o modo como os textos e as imagens, que dão a ver e pensar o real, são apropriados pelos leitores.

Em nosso estudo, entender as apropriações realizadas por Francisco Floriano de Paula acerca dos princípios de socialização e individualização implicou considerar elementos contextuais e conteúdos que circularam no Brasil, posto que possivelmente tenham alimentado sua imaginação e induzido a produção de sentidos diferenciados em relação à Escola Nova. Nessa direção, nas próximas seções procuramos analisar tais elementos e contextos.

\section{SOCIALIZAÇÃO E INDIVIDUALIZAÇÃO E O PERIGO DA DESCRISTIANIZAÇÃO}

No Brasil, projetos educativos distintos estiveram em disputa em defesa de interesses, estabelecimento de hegemonia e definição de poder. Conforme Cury (1978), nas décadas de 1920-1930, Igreja e Estado protagonizaram intensos debates e conflitos, posto que católicos e reformadores tinham concepções diferentes sobre a crise na qual a sociedade estava imersa e, consequentemente, perspectivas distintas sobre as alternativas de superação. Para os católicos, por viver o presente de forma pragmática e materialista, o homem apegava-se às coisas terrenas e desconsiderava que o futuro era a vida eterna. Daí que a salvação carregava o sentido de retorno aos valores espirituais e o serviço a Deus, sendo a Igreja a única força organizada, estável e capaz de reimpor a ordem. Para os reformadores, cujas ideias têm suas matrizes ancoradas no liberalismo, o homem vivia o presente com uma mentalidade ultrapassada, por isso a salvação encontrava-se no humanismo científico-tecnológico - a ciência e a máquina, que, apesar de seus possíveis usos abusivos ou destrutivos, guardavam em si as possibilidades de retirar o homem da crise (Cury, 1978).

Em Minas Gerais, por motivos diferentes, princípios da Escola Nova encontraram oposição na oligarquia e na Igreja católica. Por um lado, a oligarquia mineira temia que a democratização da escola pudesse levar à perda do controle sobre as massas educadas e esclarecidas. Segundo Cury (1978), o caráter social da escola e a sua abertura às camadas populares eram motivos de preocupação dos setores oligárquicos, levando seus representantes a imputarem a pecha de "comunistas" aos defensores dos ideais liberais na educação. Por outro lado, a Igreja temia perder a influência que exercia sobre a sociedade, diante do risco de descristianização da população pela expansão da rede pública de ensino, que os reformistas pretendiam leigo, obrigatório e gratuito.

Conforme Peixoto (2004), os fins da educação, a individualização e a socialização eram pontos nevrálgicos no embate da Igreja com os princípios da Escola 
Nova. Quanto às finalidades da educação, a Igreja compreendia que a Escola Nova pregava princípios contrários à educação espiritual e ao serviço a Deus. Já o temor ao individualismo e à socialização explicava-se pela ênfase escolanovista na vida natural e social, voltada ao atendimento às necessidades materiais do homem, desconsiderando questões espirituais e sobrenaturais. E essa era uma abordagem que a Igreja compreendia como deificação do homem, como tentativa de implantação do comunismo e descristianização da sociedade (Peixoto, 2004).

Para Peixoto (2004), apesar das divergências entre Igreja e Estado, o clero mineiro, sem abrir mão de seus princípios e valores, manifestou disposição em encontrar consenso, buscando pontos comuns considerados positivos na nova proposta. E, assim, por um esforço de aproximação, a Igreja identificou os métodos ativos e o princípio da educabilidade, que caracteriza o ser humano, como pontos comuns entre a Educação Nova e a proposta cristã de educação. E, nesse empreendimento conciliador, "a identificação com os métodos ativos abre à Igreja mineira a possibilidade de um recuo estratégico em seu confronto com o Estado. Ela ressignifica a pedagogia renovada, de forma a conciliar os princípios da fé e os avanços da ciência" (Peixoto, 2004, p. 285).

$\mathrm{E}$ assim, o clero mineiro desenvolveu um discurso em defesa do escolanovismo católico, que em sua visão seria capaz de aliar tradição e modernidade, preservando os valores da tradicional sociedade em Minas Gerais e abrindo-se às inovações educacionais. Os católicos passaram a defender os métodos ativos, não apenas por serem compatíveis com seus valores e ideal educacional - a atividade do aprendiz não é apresentada como algo novo, mas atribuída a São Tomás de Aquino (Peixoto, 2004).

Ainda conforme a autora, pela solução de compromisso entre Igreja e Estado, as escolas oficiais mineiras passaram a ministrar o ensino religioso como disciplina obrigatória, enquanto a Igreja colaborava com o Estado na oferta do ensino, mantendo escolas confessionais, aplicando e defendendo o ideal católico em consonância com conhecimentos da psicologia infantil e dos métodos pedagógicos advindos dessa ciência. Para o Estado, que assumiu medidas de contenção da oferta do ensino, os métodos ativos traziam o sentido de renovação e modernização, também significando a possibilidade de compromisso com a Igreja (Peixoto, 2004).

Se as metodologias renovadas deixaram de representar um problema, os fins da educação permaneceram como pontos de tensão. Assim, para conciliar interesses e pontos de vista, o governo mineiro propôs uma nova leitura para o princípio de socialização, que passou a ser compreendido como a divulgação de uma moral social, "[...] fazendo da educação um instrumento de adaptação dos indivíduos à vida social" (Peixoto, 2004, p. 288). Com esse deslocamento, o Estado pretendia demonstrar que o novo ideário, tal como compreendido e implementado nas escolas oficiais mineiras, não se chocava com os propósitos educativos católicos.

Dessa maneira, os representantes do governo mineiro passaram a disseminar valores e princípios aceitos pela Igreja. As apropriações produzidas por Francisco Floriano de Paula, apresentadas na seção anterior deste artigo, são representativas do movimento conciliador entre Igreja e Estado. A própria Revista do Ensino, órgão oficial do governo mineiro destinado à divulgação de ideias pedagógicas, assumiu 
um tom conciliador relativo aos fins da educação, também explicitando esse temor à socialização e ao comunismo pela via da escola. No ano de 1933, a revista publicou o discurso proferido por D. Joaquim Silvério de Souza na formatura de alunos do Grupo Escolar de Diamantina, em que o arcebispo explicitava suas preocupações com o comunismo e indagava: "a socialização sem restrições não irá implantando nas almas das crianças o comunismo?”. Para ele, essa questão não poderia ser descartada, pois o comunismo pressupunha o afastamento das crianças em relação aos princípios cristãos de vida, e para a sociedade seria igualmente perniciosa "a moral sem Deus e a barbaria comunista" (Souza, 1933, p. 25).

Ao discutir a possibilidade de práticas socialistas ou comunistas no âmbito da Escola Nova, Cury (1978) destaca que a utilização política da escola, visando à introdução do socialismo e do comunismo, era preocupação presente nos ideais católicos de formação da juventude brasileira, cujas ações pretendiam banir a descristianização. $\mathrm{O}$ autor afirma que a Igreja compreendia como perigosas as ideias de Rousseau, considerando-o pai do "individualismo anárquico", pois propunha que a sociedade se assentasse no contrato social livre, em que o indivíduo passava a ser fonte de sua atividade pessoal e social, sem ligação com Deus, que era princípio e fim de toda ação e autoridade. Para a Igreja, tomar a consciência individual como juiz dos atos humanos permitia a liberação das paixões e egoísmos do homem (Cury, 1978, p. 29).

Em síntese, se no Brasil os princípios da Escola Nova influenciaram o tom das disputas entre educadores católicos e leigos (Carvalho, 2004a; Cury, 1978), em Minas Gerais conduziram a uma busca de consenso entre o governo e a Igreja (Peixoto, 2003, 2004), e em Montes Claros apresentaram-se como objeto de preocupação do professor Francisco Floriano de Paula e temática de discussão no jornal Gazeta do Norte. A defesa que faz Francisco Floriano de Paula é, na expressão de Peixoto (2003), de um "escolanovismo católico", por adesão aos métodos e recursos de ensino da Escola Nova, orientado por finalidades cristãs de formação humana, voltado para a solidariedade e o serviço a Deus.

\section{SOCIALIZAÇÃO E INDIVIDUALIZAÇÃO E O TEMOR DO COMUNISMO}

No contexto investigado, pelo menos dois fatores podem ser tomados como possibilidade para explicar as apropriações realizadas por Francisco Floriano de Paula. Em primeiro lugar, conforme Chartier (2001), encontram-se os próprios textos que, em si, quase sempre, implicam polissemia e estão abertos a interpretações variadas. Como segunda via de explicação, entendemos que no momento histórico estudado (década de 1930), as ideias de socialismo e comunismo como ordenação política não podem ser desconsideradas.

Na primeira via de explicação, ao apropriar-se de concepções e princípios da Escola Nova e entender socialização como socialismo ou comunismo, pensamos que Francisco Floriano de Paula, alicerçado em seus temores acerca de doutrinas políticas não liberais, produziu significados para os textos que leu. Para Norbert Elias, o que se entende por "indivíduo" ou por "sociedade" depende, em grande parte, da forma assumida pelo que as pessoas desejam e temem (Elias, 1994). Assim, 
Francisco Floriano de Paula pode ter assumido um posicionamento ético conservador, projetando seus receios e passando a compreender que a Escola Nova poderia favorecer a implantação de doutrinas políticas. Ou seja, por temer o comunismo ou o socialismo e considerar que essa era uma ameaça real, o professor procedeu uma leitura diferenciada dos textos relativos à Escola Nova.

Chartier (2001) pondera que, ao falar de práticas de leitura, é preciso considerar que não há um sentido fixo nos textos, mas múltiplas possibilidades de sentidos e pluralidade interna da linguagem. Há textos que são abertos a reapropriações múltiplas, e há outros que não o são. Dessa forma, a construção de sentidos situa-se entre os leitores e os textos. Leitores dotados de competências específicas e identificados por suas posições e disposições; textos cujo significado se encontra dependente dos dispositivos discursivos e formais pelos quais foi escrito. "A leitura é prática criadora, atividade produtora de sentidos singulares, de significações de modo nenhum redutíveis às intenções dos autores de textos ou de fazedores dos autores de textos ou de fazedores de livros [...]" (Chartier, 1990, p. 123).

Espera-se que os leitores captem os sentidos pretendidos, que façam uma compreensão correta do texto lido. Por isso é importante reconhecer as estratégias pelas quais autores e editores procuram impor uma ortodoxia e produzir uma leitura autorizada, ou seja, o modo como procuram introduzir nos textos os condicionamentos que pretendem impedir a emergência de sentidos não pretendidos (Chartier, 1990).

Por essa inteligibilidade é possível pensar que os princípios da Escola Nova estavam sujeitos a apropriações diferenciadas. Em relação à socialização e à individualização, se considerarmos as teorizações de Lourenço Filho (1978), é possível afirmar que as apropriações de Francisco Floriano de Paula constituem-se como leituras não autorizadas. Isso porque, conforme o autor, a Escola Nova, em suas características e princípios gerais, não preconizou a implantação do comunismo ou do socialismo como doutrina política. Para o autor, a Escola Nova emprega ênfase nas relações sociais por sua grande importância na formação humana, por estarem associadas à motivação, à aprendizagem e à estruturação da personalidade.

Para orientar a compreensão dos educadores, Lourenço Filho usa estratégias explícitas para refrear sentidos e impedir uma leitura não autorizada de princípios escolanovistas. No livro Introdução ao estudo da Escola Nova (1978), o autor afirma que, ao fazer uso da expressão "social”, Durkheim não tinha a intenção de referir-se ao socialismo como regime político, destacando também que a educação era vista por esse estudioso como a socialização da criança e sua inserção em determinada cultura, tornando-a homem de seu meio, similar a seus pares. E o termo socialização não possuía qualquer conotação de ordem política, "nada tendo a ver com a ideia de regimes políticos” (Lourenço Filho, 1978, p. 128).

Ao explicitar que a expressão "social" não se referia a regimes políticos, Lourenço Filho (1978) sinaliza para essa possibilidade de compreensão, por isso explicita a inadequação desses sentidos, de forma que possa orientar o leitor e impedir "ideias erradas" e não autorizadas. Ou seja, Lourenço Filho coloca em seu texto um freio à livre interpretação do leitor, indicando-lhe chaves de leitura que 
lhe pretendiam determinar um modo de ler, evitando equívocos de compreensão, aos quais o princípio de socialização esteve sujeito.

$\mathrm{Na}$ segunda via de explicação para as apropriações de Francisco Floriano de Paula, consideramos que o contexto brasileiro da época poderia ter induzido essas leituras diferenciadas. O clima político no Brasil era propício à produção de temores sobre o comunismo, e para isso basta lembrar que em novembro de 1935 o país viveu a Intentona Comunista - insurreição político-militar promovida pelo Partido Comunista do Brasil (PCB), que visava derrubar Getúlio Vargas e instalar um governo socialista.

É fato que a Intentona Comunista ocorreu após a explicitação dos temores de Francisco Floriano de Paula, que discursou para as alunas montes-clarenses em janeiro de 1935. Contudo, é importante lembrar que o PCB foi criado em 1922 e que no final dessa década o partido já havia se fortalecido ao intensificar sua participação nas campanhas eleitorais e inserir-se no seio do proletariado urbano e em meio aos trabalhadores rurais, recebendo apoio de militantes e líderes tenentistas após a Revolução de 1930, entre eles Luis Carlos Prestes. Portanto, no período em que Francisco Floriano de Paula manifestou-se sobre o risco da entrada do comunismo pela via da escola, havia uma ambiência política favorável à instalação de rumores e temores. O "perigo vermelho" fazia parte do imaginário social e poderia desencadear ações daqueles que o temiam, mesmo se o risco pudesse parecer ilusório para muitos.

Ao discutir o modo como o anticomunismo influenciou a política externa brasileira perante os países socialistas, gerando desconfiança e constantes rupturas, Motta (2007) entende que a discussão deve partir do ano de 1917, abordar o Estado Novo, avançar até os anos da Guerra Fria, chegando até o regime militar. Não obstante o olhar mais abrangente, o autor considera:

[...] a década de 1930 e o período do Estado Novo constituem momento chave da análise, uma vez que foi durante aqueles anos que se solidificou no Brasil o anticomunismo, principalmente entre as elites sociais, políticas e burocráticas. E o temor ao comunismo foi uma das principais balizas norteadoras das políticas do Estado brasileiro em relação aos países socialistas. (Motta, 2007, p. 230)

Motta (2007) lembra que as relações entre o Brasil e a União Soviética eram complicadas. Inicialmente, o governo brasileiro recebeu, de forma positiva, a derrubada do czar em fevereiro de 1917, demonstrando simpatia pela experiência republicana posta em curso na Rússia nos meses subsequentes. No entanto, o regime político que ascendeu ao poder com a insurreição bolchevique de outubro (novembro) de 1917 não inspirou a mesma simpatia, sendo que, no ano seguinte, o Brasil rompeu relações diplomáticas. Nesse novo contexto, a imprensa brasileira divulgou histórias terríveis a respeito dos eventos revolucionários, carregando nas tintas ao descrever as violências praticadas pelos seguidores do bolchevismo. Durante a década de 1920, de forma esporádica, a imprensa publicou denúncias sobre o experimento bolchevique; período em que também circularam livros de divulgação anticomunista, geralmente de 
origem europeia. Com a Revolução de 1930, uma geração de jovens políticos e intelectuais teve a oportunidade de ocupar lugares-chave no novo contexto e, assim, após 1930, o quadro político tornou-se mais propício ao aumento da militância comunista no Brasil (Motta, 2007).

Ainda segundo o autor, por representar uma das experiências mais ousadas em curso naquele momento, a União Soviética atraiu a atenção tanto de simpatizantes quanto de detratores. Para as forças conservadoras, o socialismo era o foco principal do mal; para os anticomunistas, a União Soviética tornou-se ponto central, recebendo ataques e críticas que visaram anular os efeitos positivos da propaganda da esquerda. Dentro do Governo Vargas, as pressões contrárias vinham principalmente do Exército e do Itamaraty, que se somaram à opinião anticomunista da Igreja (Motta, 2007).

\section{CONSIDERAÇÕES FINAIS}

Neste artigo procuramos dar visibilidade para as inquietações acerca da possibilidade de descristianização e instauração do comunismo pela via da escola, resultantes de processos de apropriação dos princípios de socialização e individualização no âmbito da Escola Nova.

Da maneira como entende Chartier (2001), para a história das práticas culturais, o mais importante, frequentemente, não se pode quantificar. Assim, o fato de não podermos estabelecer a circulação do jornal Gazeta do Norte e o número de leitores que tiveram acesso ao discurso de Francisco Floriano de Paula, não inviabiliza a discussão de uma apropriação distinta por ele produzida. Ao discutir tais ideias, demarcamos apropriações, dando a ver que os processos construtivos dos sujeitos refletem os conteúdos em circulação em determinada sociedade ou época, mas também são influenciados por suas próprias operações cognitivas, inquietações, esperanças e expectativas.

O discurso de Francisco Floriano de Paula para as normalistas montes-clarenses indica o modo como ele leu os textos aos quais teve acesso e revela suas apropriações. A distância entre os princípios da Escola Nova e o modo como os assimilou refletem seus receios, que são singulares e não representativos do movimento de renovação escolanovista. Suas reflexões não são compartilhadas pelos idealizadores e defensores da Escola Nova, mas revelam inquietações que se fizeram presentes entre representantes das oligarquias e da Igreja católica, orientando representações e práticas em Minas Gerais.

\section{REFERÊNCIAS}

Chartier, R. História cultural: entre práticas e representações. Tradução de Maria Manuela Galhardo. Rio de Janeiro: Berthand do Brasil, 1990.

. Cultura escrita, literatura e história: conversas de Roger Chartier com Carlos Aguirre Anaya, Jesús Anaya Rosique, Daniel Goldin e Antonio Saborit. Porto Alegre: Artmed, 2001. 
Carvalho, M. M. C. O Manifesto e a Liga Internacional de Educação Nova. In: Xavier, M. C. (Org.). Manisfesto dos Pioneiros da Educação: um legado educacional em debate. Rio de Janeiro: Editora FGV, 2004a. p. 147-182.

.A Escola Nova no Brasil: uma perspectiva de estudo. Revista Educação em Questão, Natal: UFRN, v. 21, n. 7, p. 90-97, set./dez. 2004b. Disponível em: <https://periodicos. ufrn.br/educacaoemquestao/article/download/8382/6040>. Acesso em: ago. 2017.

Cury, C. R. J. Ideologia e educação brasileira: católicos e liberais. São Paulo: Cortez e Moraes Ltda., 1978.

Elias, N. A sociedade dos indivíduos. Rio de Janeiro: Jorge Zahar, 1994.

Lopes, E. M. T. O escolanovismo: revisão crítica. In: Mello, G. N. Escola Nova, tecnicismo e educação compensatória. São Paulo: Edições Loyola, s/d. p. 19-28.

Lourenço Filho, M. B. Introdução ao estudo da Escola Nova: bases, sistemas e diretrizes da pedagogia contemporânea. 12. ed. São Paulo: Melhoramentos; Rio de Janeiro: Fundação Nacional de Material Escolar, 1978.

Мотта, R. P. S. O perigo é vermelho e vem de fora: O Brasil e a URSS. Locus: Revista de História, Juiz de Fora: UFJF, v. 13, n. 2, p. 227-246, 2007. Disponível em: <http:// www.uff.br/locus/files/2010/02/131.pdf>. Acesso em: set. 2016.

Peixoto, A.M.C.Educação e Estado Novo em Minas Gerais. Bragança Paulista: EDUSF, 2003.

. A reação de Minas ao Manifesto dos Pioneiros de Educação Nova. In: Xavier, M. C. (Org.). Manisfesto dos Pioneiros da Educaşão: um legado educacional em debate. Rio de Janeiro: Editora FGV, 2004. p. 271-300.

VArela, J. Categorias espaço temporais e socialização escolar: do individualismo ao narcisismo. In: Costa, M. V. (Org.). Escola básica na virada do século. São Paulo: Cortez, 2003. p. 73-106.

\section{DOCUMENTOS CONSULTADOS}

Alves, G. A festa das normalistas. Gazeta do Norte, Montes Claros, ano IX, n. 506, 12 fev. 1927. Discurso da alumna Geraldina Alves.

Canella, J. A escola, meio social. Gazeta do Norte, Montes Claros, ano XVI, n. 859, 15 abr. 1933. Collumna Pedagógica.

Guimarães, A. Socializar a creança. Gazeta do Norte, Montes Claros, ano XV, n. 861, 29 abr. 1933. Collumna Pedagógica.

Madureira, J. Palestrando com professoras. Revista do Ensino, órgão oficial da Inspetoria Geral da Instrução, ano VII, n. 92, 15 jul. 1933.

Maciel, I. A linguagem como instrumento de communicação. Gazeta do Norte, Montes Claros, ano XV, n. 856, 25 mar. 1933.

Netto, J. R. Pela Instrucção. Escola Normal Official. Gazeta do Norte, Montes Claros, ano XVII, n. 925, 11 ago. 1934.

. Pela Instrucção. Normalistas de 1934. Gazeta do Norte, Montes Claros, ano XVI, n. 946, 5 jan. 1935. 
Paula, F. F. Discurso pronunciado em formatura das normalistas de 1934. Gazeta do Norte, Montes Claros, ano XVII, n. 948, 19 jan. 1935.

Souza, J. S. Discurso de paraninfo às diplomandas do Grupo Escolar de Diamantina. Revista do Ensino, ano VII, n. 79, p. 21-27, $1^{\circ}$ jan. 1933.

\section{SOBRE AS AUTORAS}

Geisa Magela Veloso é doutora em educação pela Universidade Federal de Minas Gerais (UFMG). Professora da Universidade Estadual de Montes Claros (UNIMONTES)

E-mail: velosogeisa@gmail.com

Cynthia Greive Veiga é doutora em história pela Universidade Estadual de Campinas (UNICAMP).Professora da Universidade Federal de Minas Gerais (UFMG). E-mail: greive@fae.ufmg.br

Maria Aparecida Paiva é doutora em literatura comparada pela Universidade Federal de Minas Gerais (UFMG). Professora da mesma instituição. E-mail: paiva.aparecida@gmail.com

Recebido em 26 de setembro de 2016 Aprovado em 8 de setembro de 2017 